\title{
A Retrospective Study of Treatment Complexity and Efficiency in a Brazilian Undergraduate Comprehensive Dental Care Program
}

\author{
Sandra Cristina Guimarães Bahia Reis, Laura Barbosa Santos, and Cláudio Rodrigues Leles
}

School of Dentistry, Federal University of Goias, 74605-220 Goiania, GO, Brazil

Correspondence should be addressed to Cláudio Rodrigues Leles, crleles@odonto.ufg.br

Received 9 April 2011; Accepted 16 June 2011

Academic Editor: Susan Hallam

Copyright (๑) 2011 Sandra Cristina Guimarães Bahia Reis et al. This is an open access article distributed under the Creative Commons Attribution License, which permits unrestricted use, distribution, and reproduction in any medium, provided the original work is properly cited.

\begin{abstract}
The aim of the study was to explore treatment efficiency in an undergraduate comprehensive dental care program (CDCP). The study sample consisted of the records of 652 patients from the CDCP of the School of Dentistry, Federal University of Goias, Brazil, who were treated in the period from 2004 through 2009. A total of 45 clinical procedures performed by the students was listed and a panel of 19 judges, graded the perceived complexity of each procedure on a 11-point scale using an adaptation of the Thurstone method. Spearman's correlation, one-way Anova, Kaplan-Meier, and Cox regression were used to build a predictive model for timeto-event data-completion of treatment (CT). Treatment time for CT was correlated with complexity scores $(r=0.60 ; P<0.001)$. The average estimated median months for CT was $23.0(95 \% \mathrm{CI}=19.6-26.3)$ and was significantly different $(P<0.001)$ among complexity levels (low 13.0, intermediary 19.0, high 47.0). When low complexity was the reference category, estimated changes in risk for incomplete treatment were greater for intermediary $(\mathrm{HR}=0.54 ; 95 \% \mathrm{CI}=0.40-0.75)$ and high complexity cases $(\mathrm{HR}=0.32 ; 95 \% \mathrm{CI}=0.23-0.45)$. The results indicated that treatment complexity has a large influence on undergraduate $\mathrm{CDCP}$ efficiency and should be considered when planning organizational strategies for the clinical environment.
\end{abstract}

\section{Introduction}

Undergraduate comprehensive dental care is an instructional program that aims to provide appropriate care for patients' general dental needs. In the Comprehensive Dental Care Program (CDCP), students have the opportunity to become familiar with their future clinical practice and to develop not only technical skills, but also professionalism, ethics, time management, critical thinking, decision making, and interpersonal and communication skills [1].

Assessments of CDCP usually focus on productivity [2, 3 ], patient satisfaction [4-6], or quality of care [7]. Other studies explored factors affecting efficiency of care, based on the completion of treatment [8] and ratio of visits to patients [7]. In CDCP settings, efficiency may be associated with completion of treatment with fewer visits and in shorter time periods. Compared with services provided by dental graduates, care provided by students may require more time and more visits [7]. In addition to the fact that students are less productive, other intrinsic characteristics of the clinical setting may affect the efficiency of care such as patient selection criteria, financial and human resources, clinical assistance boundaries, tutorship arrangements, and technical resources.

In addition, standards of efficiency of care must be compatible with academic requirements of the dental curriculum. An appropriate balance between high-quality dental education and effective care is a major challenge for many dental schools. In Brazil, educational policies for health care areas are required to be in line with national health system policies, particularly in public schools. Brazilian Curriculum Guidelines for Dentistry [9] reinforce that schools must graduate dental professionals who have a comprehensive view of community needs, general abilities, and competencies, and who are able to promote sensitive comprehensive care and can work cooperatively with other health professionals to promote effective health care.

In 2006, the Commission on Change and Innovation in Dental Education of the American Dental Education Association (ADEA) identified the need for changes in dental 
education concerning the challenges of funding and limited access, marginalization of dentistry as a specialized health care service unavailable to the poor, and the nature of dental education itself, described as convoluted, expensive, and dissatisfying to students [10]. Factors such as inflexible and overcrowded curricula, lack of student autonomy, passive learning environments, and lack of effective connectivity among dental clinical areas commonly decreased efficiency of care by inhibiting the ability of students and tutors to complete treatments in reasonable amounts of time.

Although curriculum changes are mandatory, appropriate selection of patients according to different treatment complexity levels may be an effective way to improve treatment efficiency, student productivity, and patient satisfaction. In addition, appropriate patient selection might stimulate environmental reorganization and improve the management of clinical setting routines. Thus, the aim of this study was to investigate efficiency of care with respect to the completion of treatment in a CDCP in a Brazilian public dental school and to explore the influence of treatment complexity on time and rate of treatment completion.

\section{Material and Methods}

A retrospective cohort study was designed to include all patients from 2004 through 2009 who attended the CDCP of the School of Dentistry, Federal University of Goias, located in the midwestern region of Brazil. The study protocol was approved by the School's ethical research committee.

This public dental school has a five-year curriculum, and the CDCP is in the last two years. The clinical setting has 32 complete dental equipments for 60 students; the sets are distributed in separate rooms and common areas that are used for dental materials and to scrub instruments. About eight tutors supervise clinical work, and the patients are seen by two students - one as the operator and the other as the auxiliary.

The Patient Attendance Service of the school registered 1406 patients who were seen at the CDCP, including regular and conditional patients. All of these patients had made appointments for treatment. Patients were excluded in the following cases: no initial appointment with clinical examination registration $(n=269)$, patients with treatment initiated in another clinic of the school $(n=146)$, screened patients with treatment not initiated $(n=79)$, conditional patients $(n=147)$, and patients with incomplete data $(n=$ 133). Data were gathered from July 2009 through April 2010.

Three trained research assistants participated in data collection and retrieved the following information from the patient's dental records: patient identification, initial clinical conditions, treatment plan, treatment procedures, number of appointments, time in months of treatment, dates of the first and last appointment, and treatment status (completed or not completed). Treatment was considered completed when the prescribed treatment plan was fully accomplished and the case was registered as completed in the patient record.

Treatment procedures were categorized according to the Brazilian Dental Association reference document [11]. A list
45 treatment procedures was obtained, and the frequency of each procedure was recorded by patient. In the next step, an adaptation of the Thurstone method for scaling was used to measure the relative complexity of the entire treatment for each patient [12]. The method is based on the assumption that the distribution of attitudes of a group on a specific issue may be represented by a frequency distribution. The scale was constructed to represent the students' and the tutors' attitudes toward the performance of dental procedures in the CDCP environment, including aspects such as the difficulties associated with the tasks relative to the specific procedures and the time consumed to complete them.

A group of 19 judges (10 tutors and 9 students) agreed to have their attitudes measured relative to their judgment of treatment complexity. They received a letter with instructions and an explanation of the scaling process. Lists containing the 45 dental procedures were presented in a random order to the judges. Procedures were typed on small slips, one procedure on each slip. A set of these 45 slips was given to each judge. They were also given eleven master slips of the same size numbered from 1 to 11 . Only two of these slips were labeled as to the kind of opinions that should be placed on them, namely, 1, which contained the statement "This pile expresses most simple procedures," and 11, which contained the statement, "This pile expresses the most complex procedures." The judges were asked to sort the 45 procedures into eleven piles to represent an evenly graduated series of attitudes from those procedures considered by them as extremely simple (first pile) to those which are very complex (last pile) in the CDC context. The subjects were free to adjust the slips in the piles so that the intervals in attitudes from one pile to the next seemed to be equal. The subjects were also instructed not to try to place the same number in each pile, as the slips should not be evenly distributed [12].

The returns were tabulated so as to show for each judge the pile in which every one of the 45 procedures was placed to represent the complexity score of each procedure. A mean score was obtained by summing the scores of the judges for each procedure and divided by the number (19) of judges. The mean score of the procedure was then multiplied by the number of procedures performed in each patient, and a summative score was obtained to represent the final patient complexity score for each patient.

Exploratory analysis was used to check data inconsistencies and distribution, to codify variables, and to create variable categories. Descriptive analysis was used to describe the main quantitative features of the data. Inferential analysis included Spearman's correlation, one-way Anova, KaplanMeier survival analysis, and Cox regression which were used to build a predictive model for time-to-event data. Cox regression was used to investigate the effect of treatment complexity upon the time probability to complete treatment. For the estimation of time for completion (CT), the date of the first treatment appointment until the last treatment appointment with patient discharge from treatment (terminal event) or last appointment without treatment finalization (censored cases) considered. The censored cases included patients under treatment at the end of data collection, patients who abandoned the treatment, and patients with 
TABLe 1: Patient characteristics.

\begin{tabular}{lcc}
\hline Variables & & $n(\%)$ \\
\hline \multirow{2}{*}{ Gender } & Male & $210(32.2)$ \\
& Female & $442(67.8)$ \\
\hline \multirow{2}{*}{ Age in years } & Less than 20 & $50(7.6)$ \\
& $21-30$ & $98(15.0)$ \\
& $31-40$ & $171(26.2)$ \\
& $41-50$ & $168(25.7)$ \\
Treatment status & $51-60$ & $94(14.4)$ \\
& More than 60 & $71(10.8)$ \\
\hline \multirow{2}{*}{ Time of treatment* } & Completed & $253(38.8)$ \\
& Not completed & $399(61.2)$ \\
\hline \multirow{2}{*}{ Number of appointments** } & Completed & $21.7(16.0)$ \\
& All patients & $23.2(15.0)$ \\
\hline
\end{tabular}

${ }^{*}$ In months. ${ }^{* *}$ Expressed as mean and standard deviation (in parenthesis).

treatment interrupted. SPSS 17.0 software was used to construct the database and for data analysis.

\section{Results}

Of the final study sample (652 patients), 253 (38.8\%) had completed treatment. Table 1 describes their demographics and treatment characteristics. Patients were mainly female and middle aged (mean 40.9 years; SD 14.4). The time of treatment ranged from 1 to 249 months, and the number of appointments per patient ranged from 1 to 102. Frequency analysis of time of treatment and number of appointment resulted in left-skewed distributions (Figure 1), and no significant difference was observed for time of treatment and number of appointments between completed and not completed treatment cases. There was, however, a significant association between time of treatment and number of appointments $(r=0.67 ; P<0.001)$, indicating that the longer the time of treatment, the more appointments there are per patient.

The results of the scaling process by the judges are shown in Table 2, representing the rank distribution of the 45 clinical procedures performed by students, ordered by the mean scores of each procedure. Median values of the complexity scores depict the side of the asymmetry of the distribution of the scores assigned by the judges to each procedure. The mean scores ranged from 1.0 (chairside oral hygiene orientation and topical fluoride application) to 10.3 (endodontic retreatment of posterior teeth).

The summative complexity scores ranged from 4.0 to 306.9 (mean 73.4; SD 55.7), also showing a left-skewed distribution. Figure 2 shows that complexity scores were positively correlated with time of treatment $(r=0.60$; $P<0.001)$ and number of appointments $(r=0.83$; $P<$ 0.001 ). Subsequently, a new variable was created to categorize the complexity score variable by dividing the cases into equal percentiles based on scanned cases, thus generating
TABLE 2: Distribution of complexity scores for clinical procedures ranked by judges, listed in descending order of the complexity score.

\begin{tabular}{|c|c|c|c|}
\hline & Procedure & $\begin{array}{c}\text { Mean } \\
(\mathrm{SD})\end{array}$ & Median \\
\hline 1 & Endodontic retreatment of posterior teeth & $10.3(1.0)$ & 11.00 \\
\hline 2 & Endodontic treatment of posterior teeth & $9.6(1.4)$ & 10.00 \\
\hline 3 & Fixed partial denture & $9.5(1.7)$ & 10.00 \\
\hline 4 & Crown lengthening & $8.6(1.6)$ & 8.50 \\
\hline 5 & Removable partial denture & $8.4(2.0)$ & 9.00 \\
\hline 6 & Complete denture & $8.4(2.1)$ & 9.00 \\
\hline 7 & Endodontic retreatment of anterior teeth & $7.9(1.9)$ & 8.50 \\
\hline 8 & Metallic indirect post & $7.7(1.7)$ & 8.00 \\
\hline 9 & Gingivectomy & $7.7(1.7)$ & 7.00 \\
\hline 10 & Indirect resin restoration & $7.7(1.8)$ & 7.00 \\
\hline 11 & Extraction posterior teeth & $7.6(2.5)$ & 8.00 \\
\hline 12 & Gingivoplasty & $7.5(2.5)$ & 7.50 \\
\hline 13 & Frenectomy & $7.3(2.1)$ & 7.50 \\
\hline 14 & Cast metallic restoration & $7.3(2.4)$ & 8.00 \\
\hline 15 & Biopsy & $7.2(2.8)$ & 7.00 \\
\hline 16 & Aesthetic facet & $8.9(1.5)$ & 9.00 \\
\hline 17 & Acrylic temporary crown & $6.8(2.7)$ & 8.00 \\
\hline 18 & Direct endodontic post & $6.7(1.9)$ & 6.00 \\
\hline 19 & Acrylic removable partial denture & $6.4(1.9)$ & 7.00 \\
\hline 20 & Endodontic treatment of anterior teeth & $6.1(2.2)$ & 6.00 \\
\hline 21 & Internal bleaching & $6.1(1.8)$ & 6.00 \\
\hline 22 & Subgingival debridement & $6.0(2.6)$ & 6.00 \\
\hline 23 & Class IV composite resin restoration & $5.7(2.4)$ & 6.00 \\
\hline 24 & Class VI composite resin restoration & $5.3(2.4)$ & 5.00 \\
\hline 25 & Class VI amalgam restoration & $5.3(2.6)$ & 5.00 \\
\hline 26 & Endodontic treatment of anterior teeth & $5.2(2.1)$ & 6.00 \\
\hline 27 & Class III composite resin restoration & $5.1(1.8)$ & 5.00 \\
\hline 28 & Class II composite resin restoration & $4.9(2.0)$ & 5.00 \\
\hline 29 & Class II amalgam restoration & $4.8(1.8)$ & 4.00 \\
\hline 30 & Treatment planning & $4.5(2.4)$ & 4.00 \\
\hline 31 & Class V amalgam restoration & $4.3(2.1)$ & 4.00 \\
\hline 32 & Class V composite resin restoration & $4.2(2.4)$ & 4.00 \\
\hline 33 & Class IV amalgam restoration & $4.0(0.0)$ & 4.00 \\
\hline 34 & Supragingival debridement & $3.3(1.6)$ & 3.00 \\
\hline 35 & Ionomer restoration & $3.3(1.6)$ & 3.00 \\
\hline 36 & Class I composite resin restoration & $3.3(1.9)$ & 3.00 \\
\hline 37 & Cervical desensibilization & $3.1(1.9)$ & 2.00 \\
\hline 38 & Class III amalgam restoration & $3.0(0.0)$ & 3.00 \\
\hline 39 & External bleaching & $3.0(1.6)$ & 2.00 \\
\hline 40 & Class I amalgam restoration & $2.9(1.6)$ & 2.00 \\
\hline 41 & Provisional direct restoration & $2.2(1.6)$ & 2.00 \\
\hline 42 & Sealant & $2.1(1.5)$ & 2.00 \\
\hline 43 & Plaque control & $2.0(1.6)$ & 1.00 \\
\hline 44 & Topical fluoride application & $1.2(0.6)$ & 1.00 \\
\hline 45 & Chairside dental hygiene orientation & $1.2(0.5)$ & 1.00 \\
\hline
\end{tabular}

categories with an equal number of cases in each group. Two cut points were used to create three ordinal categories each containing $33.3 \%$ of the cases named by their complexity 


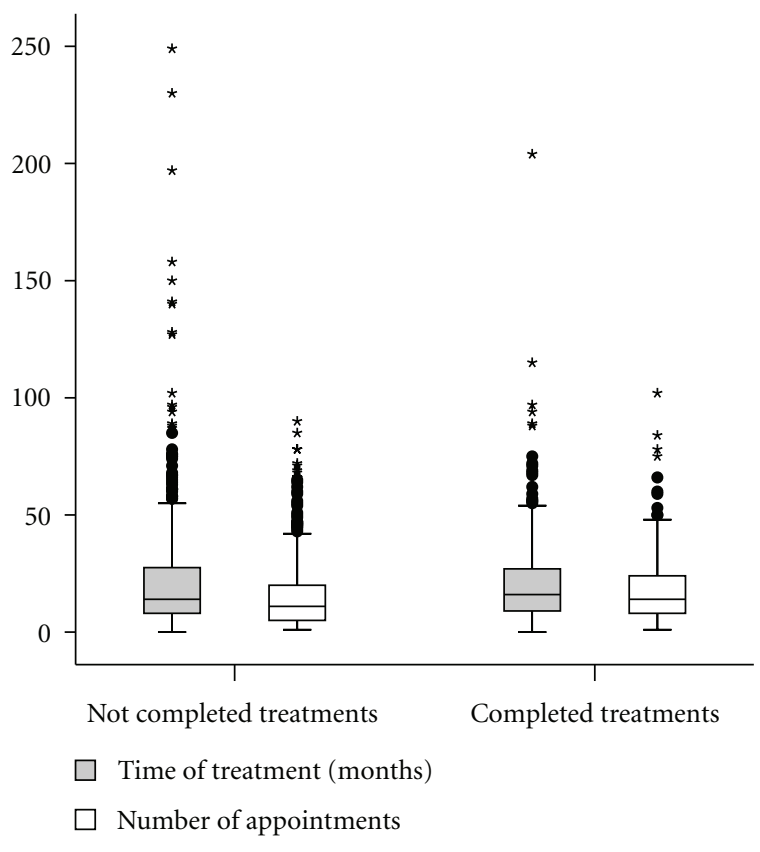

FIgURE 1: Box plot of frequency distribution for time of treatment (in months) and number of appointments for cases with completed and not completed treatments.

levels: low $(n=218)$, intermediary $(n=217)$, and high $(n=217)$. Table 3 describes the time of treatment in months among cases with treatment completed $(n=245)$ and reveals that students spent significantly more time to complete treatment $(\mathrm{CT})$ in the more complex cases $(P<$ 0.001 ). The average median (in months) for CT was 23.0 (95\%CI 19.6-26.3) and was statistically different $(P<0.001)$ among complexity levels (low 13.0, intermediary 19.0, and high 47.0).

Kaplan-Meier curves (Figure 3) showed time estimation for $\mathrm{CT}$ and revealed significant differences among different treatment complexity levels $(P<0.001)$. Cases with high complexity scores are associated with excessive prolonged treatments and low efficiency in patient care. The case processing summary of Cox regression identified 245 terminal events-completed treatment $(37.6 \%)$, 366 censored cases $(56.1 \%)$ and 41 missing cases (6.3\%). Descriptive data according to complexity level groups are shown in Table 4. Regression analysis revealed that treatment complexity is inversely associated with the likelihood of completing treatment in a shorter time period. Considering the low complexity cases as the reference category, estimated changes in risk for incomplete treatment were greater for intermediary (HR 0.54; $P<0.001$ ) and high complexity cases (HR 0.32; $P<0.001$ ).

\section{Discussion}

Overall results showed relatively low efficiency of treatment in the undergraduate CDCP, particularly for high complexity cases. In addition, excessive mean time for completing treatment was observed in all complexity groups. Inefficiency
TABLE 3: Time of treatment by complexity levels among patients who completed treatment.

\begin{tabular}{lccccc}
\hline Complexity level & $n$ & Mean (SD) & Median & $95 \% \mathrm{CI}$ & $P^{*}$ \\
\hline Low & 77 & $12.3(10.4)$ & 9.0 & $9.95-14.7$ & $<0.001$ \\
Intermediary & 77 & $18.8(19.6)$ & 14.0 & $14.3-23.2$ & \\
High & 91 & $32.1(27.0)$ & 29.0 & $26.4-37.6$ & \\
\hline Total & 245 & $21.7(22.2)$ & 15.0 & $18.9-24.4$ & \\
* One-way Anova. & & & & &
\end{tabular}

is also evidenced by the significant association between time of treatment and number of appointments, suggesting that failure in completion of treatment is not due to schedule difficulties or nonattendance.

The scaling method used to estimate complexity levels of patient treatment needs was based on the adaptation of a widely used strategy to measure attitudes in social sciences. The item scores represent the perception of complexity to perform each treatment procedure, reflecting the judges' experiences and attitudes, and ranked in terms of the intervals between them at points on a hypothetical scale [13]. The patient summative scores appeared to represent different levels of treatment complexity and to discriminate different risks in relation to treatment efficiency. Caution is urged; however, because the reliability of the scale was not demonstrated by replication among different groups of judges. In addition, caution is required because environmental and cross-cultural differences may affect the attitudes of judges toward treatment complexity.

Although factors such as appropriate quality of care and satisfactory standards of the learning process are important requirements for dental schools, undergraduates may consider the poor management of an adequate amount of time for treatment to be a major problem in patient care. Formicola et al. [14] observed that there is a generally recognized perception that the care provided by teaching clinics is inefficient, with a lack of treatment continuity as patients were passed from one student provider to another from year to year. As a consequence, patient care becomes a kind of secondary byproduct of dental education [14].

Students also perceive problems in dental education and their learning experiences in the clinical settings. Major concerns about the need to provide patient care while trying to achieve procedural requirements, the need to perform what students perceived as noneducational administrative tasks such as calling and scheduling patients, handling excessive amounts of paperwork, and working with different instructors from day to day, emerged from students who were questioned about the effectiveness of undergraduate clinical instruction in 21 American dental schools [15]. Student requirement systems based on individual dental procedures rather than overall patient treatment often fail to achieve acceptable efficiency levels of care and do not match the best interests of patients [14]. They also fail to impute the humanistic values of health care, to prepare graduates who are satisfied with their practices, or who are capable of balancing clinical competence and social sensitivity. Changes 
TABLE 4: Estimate of time for completion of treatment (CT) according to complexity levels and hazard ratios.

\begin{tabular}{|c|c|c|c|c|c|c|}
\hline \multirow[b]{2}{*}{ Complexity level } & \multirow[b]{2}{*}{ Events $(\%)$} & \multirow[b]{2}{*}{ Censored $(\%)$} & \multicolumn{2}{|c|}{ Estimation of time for CT $(95 \% \mathrm{CI})$} & \multicolumn{2}{|c|}{ Hazard ratio } \\
\hline & & & Mean & Median & $\mathrm{HR}(95 \% \mathrm{CI})$ & $P$ \\
\hline Low $(n=255)$ & $77(31.4)$ & 128 & $20.2(15.1-25,2)$ & $13.0(10.1-15.8)$ & 1 & - \\
\hline Intermediary $(n=207)$ & $77(31.4)$ & 130 & $28.8(24.0-33.7)$ & $19.0(15.2-22.7)$ & $0.54(0.40-0.75)$ & $<0.001$ \\
\hline $\operatorname{High}(n=199)$ & $91(37.2)$ & 108 & $67.6(55.7-79.5)$ & $47.0(34.8-59.1)$ & $0.32(0.23-0.45)$ & $<0.001$ \\
\hline Total $(n=661)$ & 245 & 366 & $45.2(36.4-48.6)$ & $23.0(19.6-26.3)$ & - & - \\
\hline
\end{tabular}

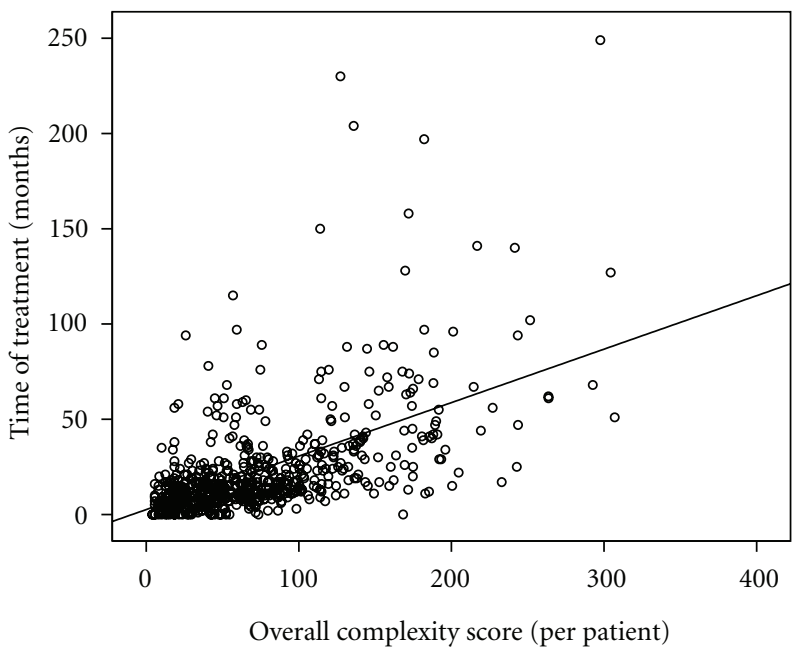

(a)

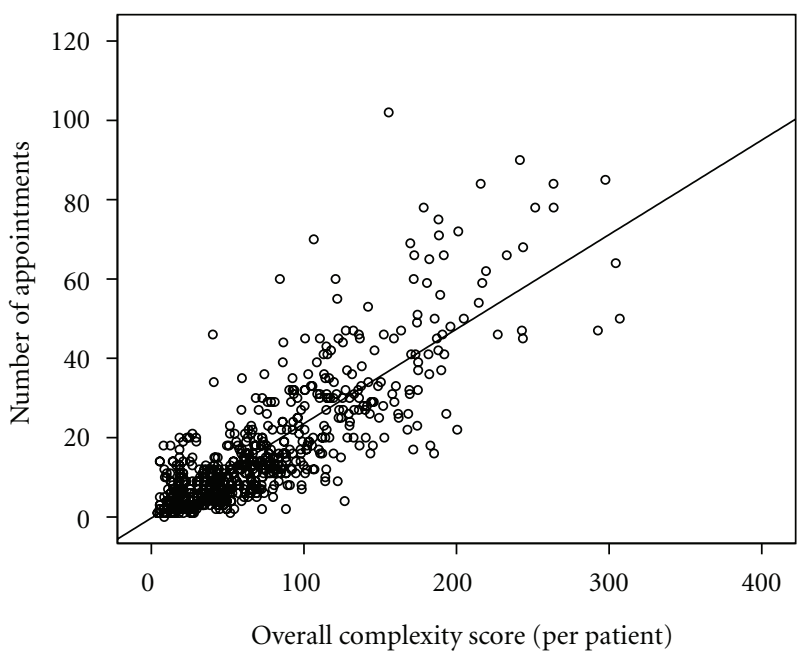

(b)

FIGURE 2: Scatterplots of the association between complexity scores and time of treatment and number of appointments.

in comprehensive care programs may improve the continuity of patient care, decrease patient clinic time, solve clinical problems, implement problem solving strategies, and produce an integrated staff who works cooperatively [16].

It was clearly observed that proper selection of patients is crucial when undergraduate clinical practice is planned to provide total patient care. The judicious screening and selection of patients are essential to provide a range of experiences and skills development for students [17].

Instruction systems based on procedures and numerical clinical requirements also have serious pitfalls. Clinical programs driven by patient needs are able to maintain satisfactory levels of quality and productivity in the absence of unit requirements and to have positive effects on academic performance $[17,18]$. Additionally, clinical instruction in community-based dental care settings has been reported to be more productive and efficient, to create the opportunity for a more diverse experience than the dental school clinic, and to positively impact student clinical competence [1922].

Low efficiency in clinical care provided by the dental school also has ethical implications in relation to payment for services. Community-based dental education and dental school-run, patient-centered delivery systems were considered viable options as models for funding dental education $[23,24]$. Payment for services usually comes from several sources, such as private insurance, patient resources, or

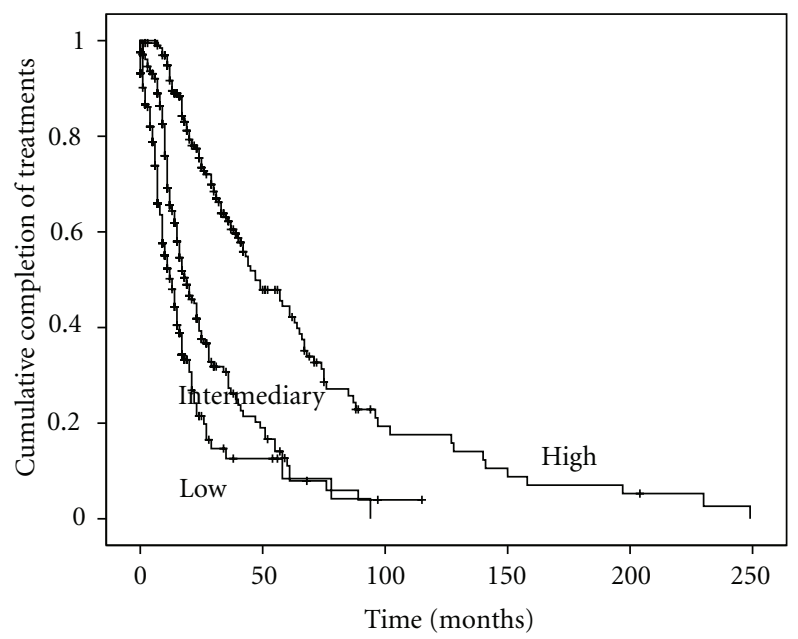

Figure 3: Kaplan-Meier curves of estimation for completion of treatment according to the complexity level (log-rank test: $P<$ 0.001).

government funding [7]. In our school, treatments are subsidized by the public health system, but the school does not recover clinic operating costs, and a great part of these costs are reimbursed by the University. In addition, students pay the costs of infection control and other clinical items 
which might also be considered a student subsidy of patient care rather than a way to finance education [7]. All these public or private sources of funding may require a reasonably efficient clinical care system that is minimally satisfying to consumers.

This study focused mainly on the efficiency assessment of the clinical care in a predoctoral comprehensive dental clinic, showing that treatment complexity exhibits great influence on undergraduate CDCP efficiency and should be considered when planning organizational strategies for clinical environments. In the future, many other issues should be addressed to learn how to provide the best dental education experience for students, faculty, and patients.

\section{References}

[1] L. W. Baughan, B. A. Hagan, and M. V. Dishman, "Student evaluation in the comprehensive care setting," Journal of Dental Education, vol. 57, no. 3, pp. 239-243, 1993.

[2] V. Evangelidis-Sakellson, "Student productivity under requirement and comprehensive care systems," Journal of Dental Education, vol. 63, no. 5, pp. 407-413, 1999.

[3] D. C. Holmes, R. M. Trombly, L. T. Garcia, R. L. Kluender, and C. R. Keith, "Student productivity in a comprehensive care program without numeric requirements," Journal of Dental Education, vol. 64, no. 11, pp. 745-754, 2000.

[4] F. A. Xhonga-Oja, E. Sonnabend, and H. Krapp, "Criteria leading to patient loss from dental school clinics," Journal of Oral Rehabilitation, vol. 13, no. 4, pp. 339-345, 1986.

[5] A. M. Broughton and R. J. Smales, "Comparison of dental needs with the treatments actually received," The Australian Dental Journal, vol. 36, no. 3, pp. 223-230, 1991.

[6] A. K. Mascarenhas, "Patient satisfaction with the comprehensive care model of dental care delivery," Journal of Dental Education, vol. 65, no. 11, pp. 1266-1271, 2001.

[7] M. J. Field, Dental Education at the Crossroads. Challenges and Change, National Academy Press, Washington, DC, USA, 1995.

[8] D. C. Stacey, B. A. Slome, and D. Musgrave, "Factors affecting patient completion of treatment within a student dental clinic," Journal of Dental Education, vol. 42, no. 11, pp. 609617, 1978.

[9] Brazil Ministry of Education, National Curriculum Guidelines for Dentistry Courses, 2002 (Portuguese).

[10] M. Pyle, S. C. Andrieu, D. G. Chadwick et al., "The case for change in dental education," Journal of Dental Education, vol. 70, no. 9, pp. 921-924, 2006.

[11] Brazilian Dental Association (ABO), Values for Dental Procedures, 2008 (Portuguese).

[12] L. L. Thustone and E. J. Chave, The Measurement of Attitudes, University of Chicago Press, Chicago, Ill, USA, 1929.

[13] A. N. Oppenheim, Questionnaire Design, Interviewing and Attitude Measurement, Pinter Publishers, London, UK, 1992.

[14] A. J. Formicola, R. Myers, J. F. Hasler et al., "Evolution of dental school clinics as patient care delivery centers," Journal of Dental Education, vol. 70, no. 12, pp. 1271-1288, 2006.

[15] D. Henzi, E. Davis, R. Jasinevicius, and W. Hendricson, "North American dental students' perspectives about their clinical education," Journal of Dental Education, vol. 70, no. 4, pp. 361377, 2006.
[16] L. A. Tedesco, "Issues in dental curriculum development and change," Journal of Dental Education, vol. 59, no. 1, pp. 97-147, 1995.

[17] M. A. Stacey, M. V. Morgan, and C. Wright, "The effect of clinical targets on productivity and perceptions of clinical competency," Journal of Dental Education, vol. 62, no. 6, pp. 409-414, 1998.

[18] W. W. Dodge, R. A. Dale, and W. D. Hendricson, "A preliminary study of the effect of eliminating requirements on clinical performance," Journal of Dental Education, vol. 57, no. 9, pp. 667-672, 1993.

[19] J. I. Woronuk, Y. J. Pinchbeck, and M. H. Walter, "University of Alberta dental students' outreach clinical experience: an evaluation of the program," Journal of the Canadian Dental Association, vol. 70, no. 4, pp. 233-236, 2004.

[20] J. E. DeCastro, D. Bolger, and C. A. Feldman, "Clinical competence of graduates of community-based and traditional curricula," Journal of Dental Education, vol. 69, no. 12, pp. 1324-1331, 2005.

[21] C. Y. Bean, M. L. Rowland, H. Soller et al., "Comparing fourthyear dental student productivity and experiences in a dental school with community-based clinical education," Journal of Dental Education, vol. 71, no. 8, pp. 1020-1026, 2007.

[22] R. Berg, R. L. Call, K. Maguire et al., "Impact of the University of Colorado's Advanced Clinical Training and Service (ACTS) Program on dental students' clinical experience and cognitive skills, 1994-2006," Journal of Dental Education, vol. 74, no. 4, pp. 423-433, 2010.

[23] H. L. Bailit, "Models for funding clinical dental education: what's likely and what's not," Journal of Dental Education, vol. 72, supplement 2, pp. 21-24, 2008.

[24] H. L. Bailit, T. J. Beazoglou, A. J. Formicola, and L. A. Tedesco, "Financing clinical dental education," Journal of Dental Education, vol. 72, supplement 2, pp. 128-136, 2008. 


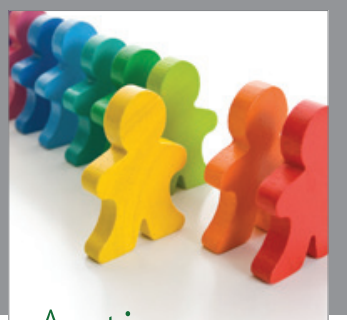

Autism

Research and Treatment
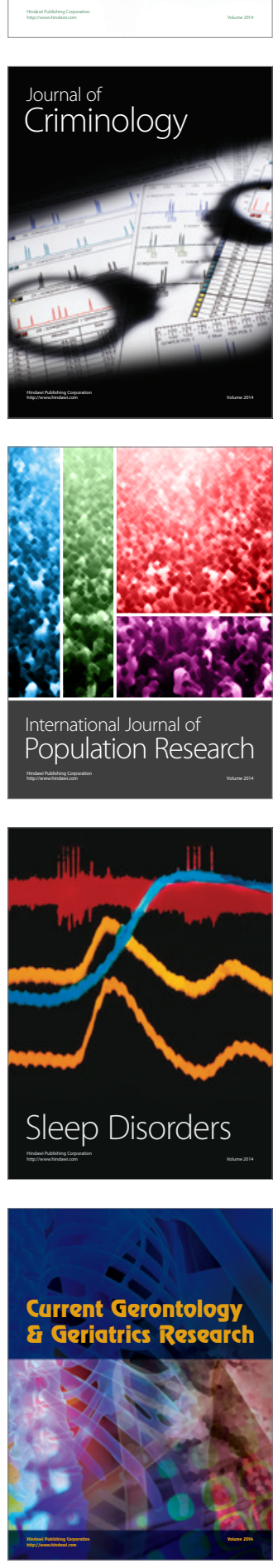
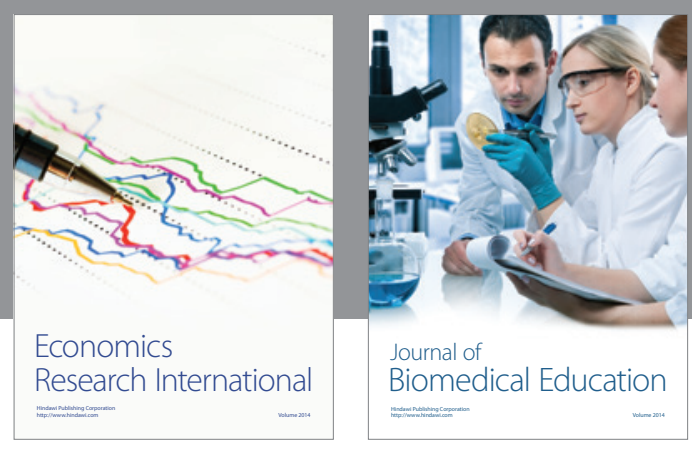

Journal of

Biomedical Education

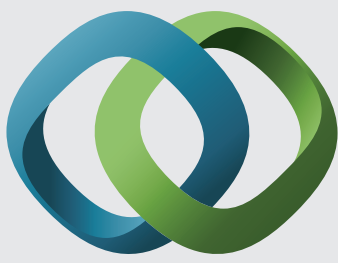

\section{Hindawi}

Submit your manuscripts at

http://www.hindawi.com
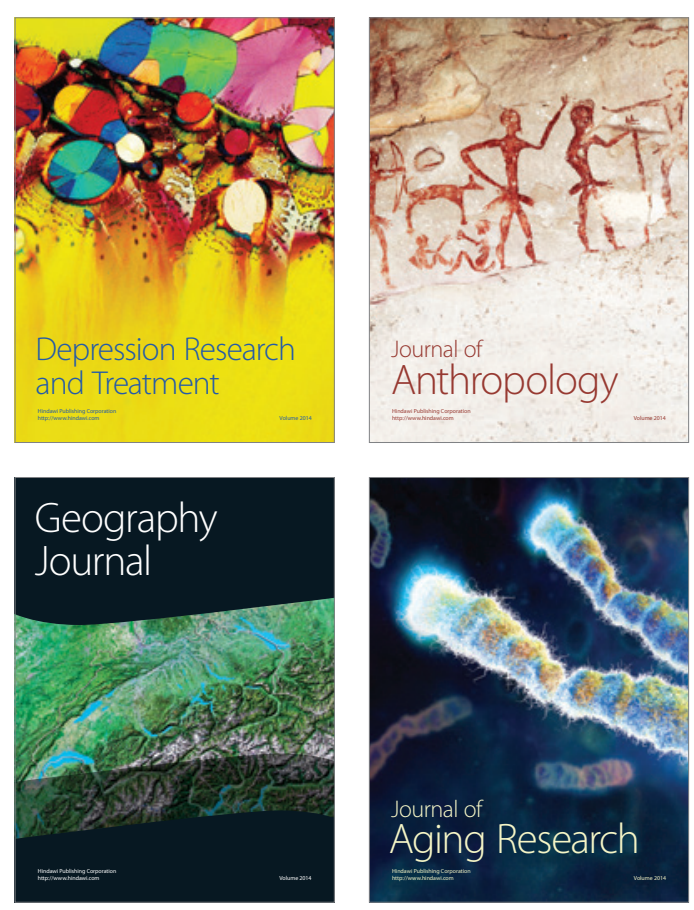

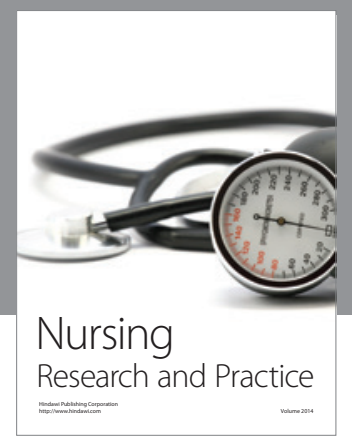

Nursing

Research and Practice

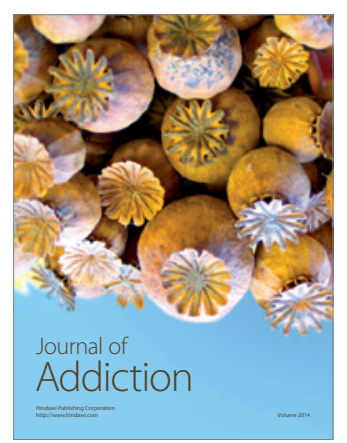

Child Development

Research

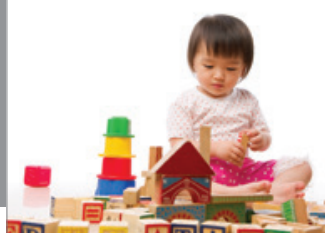

迥
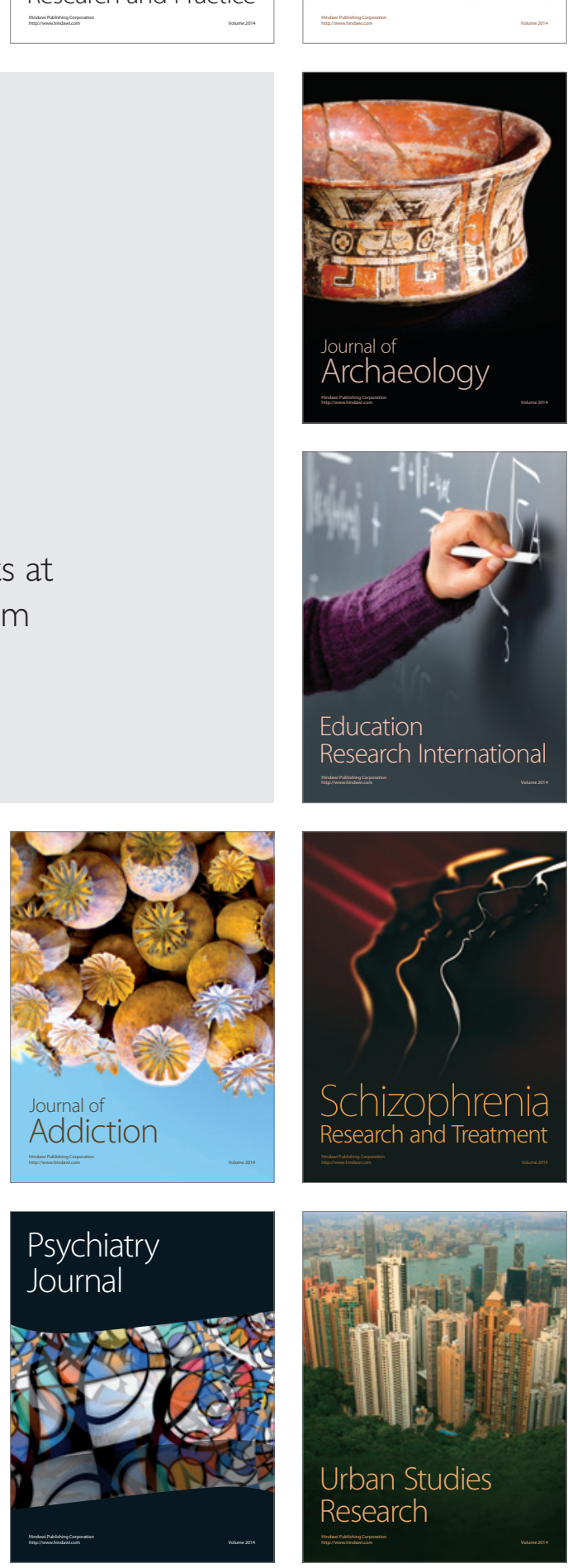